\title{
Resignificar al otro: configuraciones de la interculturalidad en la formación e intervención del trabajo social
}

\author{
Re-meaning the other: interculturality shaping in the development and \\ intervention of social work
}

Ressignificar o Outro: configurações da Interculturalidade na formação e intervenção do trabalho social

Recepción: 30/09/2019

Evaluación:09/03/2020

Aceptación: 01/04/2020

Artículo de Investigación - Revisión

https://doi.org/10.19053/01227238.10901

Fernanda Torres Gómez
http://orcid.org/0000-0003-1861-7191
Gerardo Vélez Villafañe ${ }^{2}$
http://orcid.org/0000-0002-7619-9752
Universidad de la Salle, Colombia

RESUMEN

Objetivo: Resignificar ético - políticamente la trayectoria en la comprensión del "otro" desde la formación e intervención del trabajo social, a partir del tránsito de la interculturalidad funcional hacia la interculturalidad crítica para tejer una lectura emancipadora de la alteridad que habilite la insurgencia de relaciones y subjetividades otras. Método: se recurre al análisis crítico del discurso para objetivar las comprensiones antropológicas presentes en algunos referentes teóri-

co-conceptuales adoptados y adaptados en el proceso de profesionalización del trabajo social latinoamericano. Estrategia: Se rastrea un doble proceso de subjetivación en la formación y práctica del trabajo social, identificando su contigüidad con la interculturalidad funcional, cuya superación es habilitada por la interculturalidad crítica. Originalidad: el artículo aporta de manera original a la renovación del acervo profesional crítico del trabajo social a través del problema-

1 Magíster en Docencia de la Universidad de la Salle, doctoranda en Ciencias de la Educación de la Universidad Pedagógica y Tecnológica de Colombia (UPTC). Docente-investigadora de la Universidad de la Salle. Grupo de investigación Trabajo Social, Equidad y Justicia Social. Correo electrónico: mftorres@unisalle.edu.co.

2 Magíster en Educación de la Universidad Pedagógica Nacional, estudiante de Doctorado en Educación y Sociedad, Universidad de la Salle. Docente-investigador de la Universidad de la Salle. Grupo de investigación Trabajo Social, Equidad y Justicia Social. Correo electrónico: gvelezv@unisalle.edu.co. 
tizar la producción de alteridades en la formación y práctica profesional, aspecto altamente relevante, pero pocas veces abordado rigurosamente. Se concluye que la interculturalidad crítica emerge a modo de categoría fundante que permite resignificar la alteridad como invención urdida en concepciones antropológicas eurocéntricas, abriendo paso a su multiplicidad y la emergencia de su potencia política, lo que involucra complejos desafíos a la formación profesional y la humanización de la universidad.

Palabras claves: Interculturalidad, Intervención, Trabajo Social, subjetividad, Teoría Social.
To take part from the intercultural mode from social work implies going deep into the meaning that is traditionally assigned to the "other", in a dispute regarding the shaping of subjectivities, these recognize the difference and make visible its grammatical and methodological influence in the reshaping and uncertainty what implies the social aspect. From this perspective, the present article of reflection is a product of research and teaching processes: It seeks to reshape the trajectory in the understanding of the "other" from the formation and intervention of Social Work, starting from the transition from the functional to the critical interculturality, reconstructing the stay of the social aspect under the critical perspective, to weave relationships from otherness other insurgents between subjectivities. The stated purpose was reached from the analysis of different discourses on the subject, in order to

\section{RACT}

explore and reveal the uses and abuses of power that are generated in social interactions and discourses, which are impregnated by connotations of exclusion, discrimination and domination, which are most of the time accepted and legitimized from the political level, therefore, its visibility enables emancipations and transformations in social dynamics. To conclude, it is established that in Social Work historically, conceptual denominations have been assumed that prefigure an image of the other and of professional relationships, so that the discursive plots are one of the inventive resources of the other, in which anthropological understandings linked to the political-cultural statutes of the west are included, leading to overcoming functional interculturality, towards an ethical-political commitment to critical interculturality

Keywords: Interculturality; intervention; social work; subjectivity; social theory.

\section{RESUMO}

Intervir da maneira intercultural do Serviço Social implica investigar o significado tradicionalmente atribuído ao "outro", em uma disputa sobre a configuração de subjetividades, que reconhecem a diferença e tornam visível sua incidência gramatical e metodológica na configuração e incerteza do social. Sob essa perspectiva, o presente artigo de reflexão, produto de processos de pesquisa e ensino, busca ressignificar a trajetória na compreensão do "outro" da formação e intervenção do Serviço Social, do trânsito da interculturalidade funcional à interculturalidade crítica, da passagem do social sob a perspectiva crítica, para tecer da alteridade relações outros insurgentes entre subjetividades.

O objetivo declarado foi alcançado a partir da metodologia da Análise Crítica do Discurso, que explora e revela os usos e abusos de poder gerados nas interações e nos discursos sociais, impregnados de conotações de exclusão, discriminação e dominação, que geralmente são aceitos e legitimados do nível político; portanto, sua visibilidade possibilita emancipações e transformações na dinâmica social. 
Concluindo, estabelece-se que, no Serviço Social, foram assumidas denominações conceituais que prefiguram uma imagem do outro e das relações profissionais, de modo que padrões discursivos são um dos recursos inventivos do outro, no qual incorporam-se entendimentos antropológicos interligados. Os estatutos político-culturais do Ocidente levam a superar a interculturalidade funcional, rumo a um compromisso ético-político da interculturalidade crítica.

Palavras- chave: Interculturalidade, Intervenção, Serviço Social, Subjetividade, Teoria Social.

\title{
INTRODUCCIÓN
}

Intervenir como profesional de lo social en uno de los países con mayores índices de desigualdad y exclusión de la región plantea una alta responsabilidad, que requiere de todo un repertorio de saberes y prácticas en torno a la interculturalidad para comprender, cuestionar y transformar la realidad desde la resignificación del otro en la intervención, su construcción y deconstrucción de subjetividad en lo social, y el cuestionamiento por la alteridad, asumiendo como lugar de enunciación la defensa de los derechos humanos y la búsqueda de justicia social, principios referenciados por la Association of Institutions of Social Work Education (IASSW) y la International Federation of Social Workers (IFSW), en la definición del trabajo social:

\begin{abstract}
El trabajo social es una profesión basada en la práctica y una disciplina académica que promueve el cambio y el desarrollo social, la cohesión social, y el fortalecimiento y la liberación de las personas. Los principios de la justicia social, los derechos humanos, la responsabilidad colectiva y el respeto a la diversidad son fundamentales para el trabajo social. Respaldada por las teorías del trabajo social, las ciencias sociales, las humanidades y los conocimientos indígenas, el trabajo social involucra a las personas y las estructuras para hacer frente a desafios de la vida y aumentar el bienestar. ${ }^{3}$
\end{abstract}

El trabajo social se ubica como una disciplina que investiga inmersa en las discusiones sobre la realidad y las problemáticas sociales, desde el marco epistemológico y conceptual de las Ciencias Sociales, por ello busca incidir en el cambio social desde la intervención como mediación en escenarios de alta complejidad e incertidumbre, donde se manifiesta en plenitud el sufrimiento y el dolor desde la esencia de lo humano ${ }^{4}$.

Tal intervención se expresa:

[...] como una construcción relacional que busca, desde la práctica, un tejido de saberes profesionales contextualizados, y la interacción con el otro en el campo de

3 IFSW-IASSW, "Definición global del trabajo social” (Melbourne: Reunión general, IFSW-IASSW, 2014), https://www.ifsw.org/whatis-social-work/global-definition-of-social-work/definicion-global-del-trabajo-social/

4 Edgar Malagón B., Fundamentos de trabajo social (Bogotá: Universidad Nacional de Colombia, 2012). 
lo social, para incidir y transformar objetos de intervención (problemáticas, fenómenos, manifestaciones de la cuestión social) que afectan a los sujetos y colectivos en su condición humana y dignidad, toda vez que fomenta el despliegue de las potencialidades y capacidades de los sujetos, para deconstruir dichas realidades, empoderarse y buscar la reivindicación de derechos y la justicia social. ${ }^{5}$

La intervención implica entonces generar relaciones y expectativas en el otro, en el marco del escenario de lo social como campo problémico, en el cual entran a jugar relaciones tensionantes de poder entre múltiples actores desde su dimensión política, como lo son el Estado, las instituciones, el "otro-sujeto", el sistema económico capitalista, entre otros, como lo enuncia Carballeda:

En pocas palabras, la intervención puede revelar lo que ocurre tanto en el Estado como en la sociedad; de lo que se trata es de ajustar las preguntas, dirigirlas, quizás, a nuevos horizontes donde ese "otro" objeto de la intervención, constituido a partir de la modernidad, pueda hablar otro lenguaje o expresarse en el propio. De ahí podrían surgir algunas respuestas que sirvan para ubicar la intervención en lo social en relación con una sumatoria de acontecimientos que generan nuevas incertidumbres. ${ }^{6}$

Víctor Yáñez Pereira reconoce en los procesos de intervención de trabajo social la huella de comprensiones coloniales y segmentarias de las subjetividades, toda vez que invita a atacar las lógicas instrumentales de actuación profesional que matizan el paternalismo, el asistencialismo y la institucionalización, orientadas dichas lógicas por la invisibilidad del sí profesional en relación con los otros, posible desde la reflexión, la alteridad y la integración de la investigación como correlato de la intervención, conceptuada esta como:

Proceso racional comunicativo que por vía del lenguaje, relaciona reflexiva y dinámicamente al trabajador social con una pluralidad de agentes, formando un ascendente espacio de comprensión, en cuyo espiral se enlaza un complejo de potencias y acciones que, en la forma de una estructura de saber integrado, asume el consenso como núcleo síntesis en la configuración de sentidos de realidad y de cambio, ante diversas situaciones sociales constitutivas del mundo de la vida. ${ }^{7}$

La comprensión de intervención en trabajo social implica asumir la construcción de subjetividades y la cultura como categorías relevantes en lo social, puesto que se configuran lecturas del otro enmarcadas predominantemente bajo

5 Fernanda Torres Gómez, "Reflexividad en trabajo social: horizontes desde la formación integral para la investigación y la intervención", en Reflexiones sobre la comprensión de la investigación y la intervención social en formación en Trabajo Social, ed. Maribel Florián B. (Bogotá: Ediciones Unisalle, 2018), 107.

6 Alfredo Carballeda, La intervención en lo social. Exclusión e integración en los nuevos escenarios sociales (Buenos Aires: Paidós, 2002), 35.

7 Víctor Yáñez Pereira, "Visibilidad/invisibilidad en la intervención del trabajo social: pistas para la revisitación de las pautas transaccionales de la disciplina con el mundo de lo social”, en Naturaleza, desafíos y perspectivas contemporáneas de la intervención en trabajo social. Memorias I. Seminario internacional (Buenos Aires: Editorial Lumen-Humanitas, 2011), 160. 
lógicas de interculturalidad funcional-neoliberal, definida por Tubino como "el multiculturalismo anglosajón de la acción afirmativa y la discriminación positiva. [...] busca promover el diálogo y la tolerancia sin tocar las causas de la asimetría social y cultural hoy vigentes" ${ }^{\prime \prime}$. Ante ello, emerge la apuesta por la interculturalidad crítica, conceptuada por el mismo autor como "[...] discurso no exclusivamente vinculado al diálogo entre culturas, sino que debe ser vista como un discurso preocupado por explicitar las condiciones para que ese diálogo se dé. Y esas condiciones son de índole social, económica y educativa, además de cultural"9.

Aunque en la formación de trabajadores sociales se busca generar experticias en la investigación e intervención con la interculturalidad, se identifica una fractura para vivir dicha formación en el aula, que poco reconoce las condiciones capital, social y cultural de los estudiantes, sus diferencias en escenarios como el currículo, contenidos teóricos-conceptuales, saberes y prácticas educativas que pueden promulgar intercambios desiguales en los que prima una cultura sobre otra; en ese sentido, educar desde y para la interculturalidad "posibilita identificar factores históricos, epistemológicos, axiológicos y ontológicos que reproducen patrones de poder que deshumanizan, excluyen y mantienen la esclavitud y el subdesarrollo como forma de vida insustituible y naturalizada" ${ }^{\prime 10}$.

A partir de ello, el presente artículo, producto de las investigaciones "Tramas Identitarias en Ciencias Sociales: Contextos, saberes y prácticas. El caso de Trabajo Social"11, y "Discursos educativos sobre la Interculturalidad en la Formación de Profesionales en Trabajo Social en Bogotá: Lecturas desde la Educación para la Paz"12, vinculadas al grupo de investigación Trabajo Social, Equidad y Justicia Social, busca, en un primer momento, resignificar el lugar del otro desde el análisis de las configuraciones de la interculturalidad funcional predominante en la intervención del trabajo social, para situar como apuesta ético-política la interculturalidad crítica en la significación de ese otro, consolidando, en un segundo momento, una lectura emancipadora de la alteridad producto ello de la problematización en torno a las formas de abordar objetos de investigación e intervención, puesto que traen consigo una óptica particular de cientificidad y una serie de incidencias respecto a los lugares de poder que enuncian ${ }^{13}$.

Los hallazgos esbozados en el presente documento dan cuenta de un proceso de análisis debido a que se configura como una herramienta que permite comprender y develar la complejidad de la realidad social, asumiendo que " [...]

8 Fidel Tubino, "La interculturalidad crítica como proyecto ético-político" (Lima: Encuentro continental de educadores agustinos, 2005) http://oala.villanova.edu/congresos/educación/lima-ponen-02.html (septiembre, 2019).

$9 \quad$ Ibíd.

10 María Morales Mosquera y Nora Muñoz Franco, "Desafíos para la formación desde el Trabajo Social en contextos diversos”, en Experiencias con diversidades sociales. Desde Trabajo Social Intercultural y Decolonial (Medellín: Universidad de Antioquia / Pulso \& Letra Editores, 2018), 44.

11 Investigación financiada por la Universidad de la Salle, 2018.

12 Tesis de doctorado en Ciencias de la Educación, Universidad Pedagógica y Tecnológica de Colombia, 2019.

13 Maribel Florián B., “¿Es la ciencia heteronormativa? Reflexiones en torno a cómo la teoría social contemporánea ha abordado el tema de las relaciones amorosas", en Pensar las Ciencias Humanas y Sociales. Debates interdisciplinarios, ed. Jenny Alexandra Jiménez (Bogotá: Fundación Universitaria Los Libertadores, 2015), 77-88. 
tanto los discursos como la propia tarea del analista son considerados socialmente situados y se les atribuye un papel en la (re)construcción y reproducción recursiva y recurrente de las estructuras y de la organización social"14, reconociéndose como " [...] investigación analítica sobre el discurso que estudia primariamente el modo en que el abuso del poder social, el dominio y la desigualdad son practicados, reproducidos, y ocasionalmente combatidos por los textos y el habla en el contexto social y político"15.

\section{Comprensión del otro en la intervención y formación del trabajo social: cuestionamientos a la interculturalidad funcional}

Desde una escala micro-social, puede sostenerse que el trabajo social se ha configurado históricamente como un campo de acción social profesionalizado sobre la base de una preocupación ética referida a un otro que sufre injusticias o tratos indeseables por causas socialmente producidas y socialmente superables, según Malagón ${ }^{16}$ en el contexto de la bisagra modernidad-colonialidad. La interpelación ética frente al sufrimiento socialmente impuesto y su concreción en problemáticas sociales degradantes de la existencia humana, alientan la profesionalización como forma de hacerse cargo de la vulnerabilidad (precariedad) de la existencia humana en pos de su dignificación en los campos social, cultural y político.

Esta disposición ética, que remite al ámbito de reproducción social y del cuidado en el seno del capitalismo, pliega sus sentidos y abre paso a la materialización de prácticas concretas, de conformidad con los estatutos epistémicos y culturales de la modernidad, donde opera como un mecanismo de legitimación social y un principio ordenador de la configuración teórico-metodológica de su objeto de conocimiento, de sus saberes, de los sentidos y las formas concretas de acción distintivas de su especificidad. De este modo, la disposición sensible ante el sufrimiento de otro abre paso a la urdimbre del trabajo social como profesión moderna, esto es, al desarrollo sistemático de un cuerpo de conocimientos, la institucionalización de procesos de formación profesional, la consolidación de la investigación y el reconocimiento social de la profesión ${ }^{17}$. Paralelamente, esto desemboca en un doble proceso de subjetivación del que emergen en la formación del sujeto profesional y el sujeto con quien este realizará su labor profesional.

Las huellas de este proceso de doble subjetivación pueden rastrearse a través de diversos registros filosóficos y teórico-conceptuales que, en calidad de horizontes de sentido, hegemonizan la mediación simbólica de la relación entre la

14 Luisa Martín R., "El análisis crítico del discurso. Fronteras y exclusión social en los discursos racistas", en Análisis del discurso. Manual para las ciencias sociales, ed. Lupicinio Íñiguez (Barcelona: Editorial UOC, 2006), 95.

15 Teun van Dijk, "El análisis crítico del discurso", en Estudios sobre el discurso. Una introducción interdisciplinaria, comp. y prólogo Teun van Dijk (Barcelona: Gedisa, 2000), 23.

16 Malagón, Fundamentos.

17 Bibiana Travi, La dimensión técnico-instrumental en Trabajo Social. Reflexiones y propuestas acerca de la entrevista, la observación, el registro y el informe social (Buenos Aires: Espacio Editorial, 2012). 
preocupación ética y la dimensión técnico-instrumental en la que se patenta el trabajo social como práctica profesional moderna. Lo anterior, por cuanto tales registros comportan concepciones antropológicas, cuyos significados responden a la impronta de su contexto sociohistórico y político-económico, reforzándolo o participando - abierta o veladamente - en la disputa por su redefinición.

Al decir de Gramsci y Benjamín, los horizontes de sentido se pliegan moralmente a las valoraciones definidas por las relaciones de fuerza imperantes, de modo que escapan a la neutralidad (aunque tienden a reproducirla ideológicamente) en pos de hegemonizar la significación y, con ella, definir los límites cognitivo-afectivos de comprensión de lo material-concreto mediante el lenguaje como instancia para adquirir consciencia de la existencia propia y de la realidad como un todo consistente.

En este sentido, y en virtud de sus dimensiones semántica y pragmática, las teorías y conceptos no son solo elaboraciones analíticas cuya formalización científica hace objetivable-legible algún aspecto de la realidad para su explicación o comprensión disciplinar-profesional, sino también diseños estratégicos históricamente contingentes, que prescriben y proscriben formas de acción con efectos en la estructuración de lo sociohistóricamente existente. No obstante, ello no pretende desconocer que la realidad social y nuestro desempeño en ella no proceden exclusivamente por vías teóricas, por cuanto los procesos de subjetivación y las prácticas cotidianas (incluidas las profesionales) se estructuran con recurso a la articulación discursiva de múltiples referentes de significación adscritos al mundo de la vida, tales como los normativos (o de política pública), visiones institucionales, juegos del lenguaje, adscripciones políticas o referentes subjetivos desplegados coyunturalmente en una ecología de relaciones de fuerza histórico-culturalmente producidas. En efecto, el doble proceso de subjetivación, del que emergen el sujeto profesional y el sujeto con quien este realizará su trabajo, acontece en una compleja trama de significaciones que evidencia una densidad hermenéutica referida a las múltiples capas, articulaciones discursivas, espacialidades y temporalidades de significación, cuya comprensión excede los alcances del presente trabajo.

Pese a esto, estamos en condiciones de avanzar en el análisis crítico de las comprensiones antropológicas presentes en algunos de los referentes teórico-conceptuales de la filosofía y las ciencias sociales adoptados y adaptados en el proceso de profesionalización del trabajo social latinoamericano ${ }^{18}$.

Si bien el conjunto de corrientes teórico-metodológicas de análisis es amplio y podría agruparse en corrientes epistemológicas, comprensiones históricas del trabajo social y de sus roles nos limitaremos al abordaje de algunas de las más representativas provenientes de lo que Netto denomina primera y segunda modernidad, agrupadas en la caracterización planteada por Lutz ${ }^{19}$, a saber:

18 Vale decir que en este abordaje prescindimos del análisis de las comprensiones antropológicas presentes en el momento fundacional del servicio social latinoamericano, pautado por la conducción ideológica de la Iglesia católica en alianza con el estado liberal, bajo un carácter confesional, anticomunista y filantrópico al servicio de la reproducción social del capitalismo.

19 Bruno Lutz, "Estructura y Sujeto: Perspectivas teóricas desde las ciencias sociales", Cinta de Moebio. Revista de Epistemología de las Ciencias Sociales n. ${ }^{\circ} 29$ (2007). 
hermenéuticas nomotéticas, híbridas y polimorfas. Las primeras se refieren al conjunto de perspectivas analíticas y metodológicas correspondientes al paradigma empírico-analítico, centradas en la abstracción científica de la legaliformidad universal que opera como base explicativa (de determinación monocausal) de lo social como realidad positiva en un contexto pautado por el liberalismo, la institucionalización cognitiva y social de las ciencias para explicar los efectos de la revolución industrial e introducir modificaciones en el funcionamiento social, la liberalización de la fuerza de trabajo, la configuración del estado de derecho y la emergencia de la ciudadanía como personalidad jurídica. Por su parte, las hermenéuticas híbridas toman distancia de las primeras para ampliar el rango explicativo de lo social más allá del determinismo y del individualismo metodológico, introduciendo la sospecha crítica (como potencia liberadora) sobre la relación sujeto-sociedad, la moderna visión logocentrada y las dinámicas de explotación-alienación capitalista.

En el marco de las hermenéuticas nomotéticas se identifican esfuerzos de explicación de lo social a partir de las leyes universales que determinan su existencia como hechos positivos (Comte), naturales (Spencer) y sociales (Durkheim). Es así como Comte, en perspectiva reformista, aboga por la búsqueda racional de leyes físicas que, al regir los hechos positivos del orden social, determinan el progreso de la humanidad y afectan la conducta del individuo sin determinar su voluntad.

Por su parte, Spencer y L. Morgan sostienen que las sociedades humanas y sus individuos, en tanto que organismos vivos, obedecen históricamente a las fuerzas naturales de la evolución: una progresión diacrónica de etapas hacia el incremento-complejización de los niveles cualitativos que determina la superioridad de unas sociedades y sus estructuras (civilizadas) sobre otras (tribales, salvajes, bárbaras). Análogamente, los individuos son naturalmente jerarquizados por una valoración social de sus aptitudes personales, lo cual produce una subordinación diferenciada.

Así mismo, Durkheim y Marx confluyen en su vocación de explicación objetiva de lo social a partir de fuerzas externas a los sujetos, que operan con independencia de su voluntad, bien por la introyección de los componentes inmateriales que cohesionan y dan forma a las sociedades (Durkheim), bien desde el materialismo histórico y dialéctico, en el que lo social (como producción de condiciones sociales de existencia) responde a una doble determinación (material e histórica) y contradicciones producidas por la actividad humana en torno a las bases materiales y relaciones necesarias para el soporte de la vida (Marx), donde, tal como sostienen Marilda Iamamoto ${ }^{20}$, Elisabete Borgianni y Carlos Montaño ${ }^{21}$, la configuración histórica del servicio social (antecedente del trabajo social) como espacio sociolaboral acontece durante la segunda post-

20 Marilda Iamamoto, Servicio social y división del trabajo. Un análisis crítico de sus fundamentos (São Paulo: Cortez Editora, 1997).

21 Carlos Montaño y Elisabete Borgianni, El debate metodológico de los 80/90. El enfoque ontológico versus el abordaje epistemológico. Metodología y servicio social hoy en debate (São Paulo: Cortez Editora, 2000). 
guerra mundial, obedeciendo a la expansión del capitalismo monopolista como respuesta tecnoprofesional paliativa a las manifestaciones de la cuestión social.

A la luz de estos racionamientos, significativamente imbuidos de referencias empírico-analíticas en el ámbito de la sociología clásica, se afirma una comprensión determinista en la que se confiere primacía a las condiciones generales del orden social (la sociedad) por sobre el ser humano, desterrándolo de lo social:

\begin{abstract}
Al margen de la forma en que se conciben lo social y la sociedad moderna, parece evidente que con tal desarrollo conceptual el ser humano quede excluido desde un inicio. Si, por una parte, lo social toma la forma de procesos sociales (Comte), del trabajo (Marx), de hechos (Durkheim) o acciones sociales (Weber); y por otra parte la sociedad moderna adquiere la forma del estadio positivo de la humanidad (Comte), del capitalismo (Marx), de una solidaridad orgánica (Durkheim) o de procesos de racionalización (Weber), resulta en términos abstractos baladi, toda vez que la supremacía de la realidad social conlleva una demarcación clara respecto de la esfera de lo humano en cuanto tal. ${ }^{22}$
\end{abstract}

Al asumir la teoría sociológica clásica, y de manera análoga la teorización estructural funcionalista reciente como una de las bases científicas de la profesión (inicialmente asumidas en disposición de reflexión ética), el trabajo social introdujo referentes de sentido a partir de los cuales la intervención profesional devino en un dispositivo reformista, histórico-socialmente determinado para secundar el progreso natural de las fuerzas sociales e históricas, reproduciendo los mandatos macroestructurales de la modernidad en materia de construcción de la nación sobre la base de procesos de individuación (reconocimiento de la responsabilidad individual) y ciudadanización, esto es, la adquisición de una personalidad jurídica tributaria de derechos y susceptible de ser administrada-controlada por instituciones gubernamentales habilitadas para "censar, clasificar y también castigar". Aquí, el sujeto se afirma universalmente como entidad racional pasivamente receptora de orientaciones sociales, políticas y culturales, trazando una relación unidireccional de transferencia (condicionada y limitada) de recursos simbólicos y materiales desde las instituciones u organizaciones, mediante el profesional, hacia una población individualizada que los requiere para adaptar su conducta al contexto social por vía del saber experto.

Por otra parte, las hermenéuticas híbridas, correspondientes a la segunda modernidad, emergen a la luz del reconocimiento crítico de la problemática configuración social propiciada por la primera modernidad, donde el veloz incremento de la riqueza acontecía en paralelo con la pauperización social a gran escala en un contexto de industrialización. En este nuevo escenario, lejos de la vivencia de las promesas de la modernidad (igualdad, fraternidad y libertad), se afirmaba la deshumanización por dinámicas de enajenación, explotación y alienación capitalista, bajo la racionalización positivista y la activación de diversas

22 Rafael Alvear, "La sociología clásica y el destierro del ser humano", Cinta de Moebio. Revista de Epistemología de las Ciencias Sociales n. ${ }^{\circ} 59$ (2017): 245. 
formas de administración tecnocrática centralista de la vida cotidiana al servicio de la primacía del mundo del trabajo.

En este escenario, adquieren particular notoriedad la teoría crítica, desde la cual se afirma que la racionalidad técnico-instrumental, que subyace en la ciencia positiva, es una lógica formal de deshumanización capitalista, difundida por la cultura de masas y en cuyas tramas la extensión antropológica (social y económica) del dominio de la naturaleza da lugar a un sujeto ideológicamente cosificado en tres esferas vitales: (1) laboral/económica, donde es unidimensionalizado y explotado como homo faber; (2) pública, como ciudadano administrado, y (3) esfera psíquica, como sujeto enfermo, cuyas pulsiones son permanentemente reprimidas.

Como sostiene Galafassi:

[...] el hombre concreto despojado de los medios de producción no es más el sujeto de la actividad productora, sino un simple elemento material de dicha actividad. Pero ya no se trataría de la sociedad industrial dividida en clases de propietarios y explotados; la crítica teórica frankfurtiana va más allá, apuntando al problema más radical de la sociedad industrial como modelo paradigmático de una racionalidad opresiva, que se ha convertido en la única regla de juego para el ejercicio, ya imposible, de una humanidad integral. ${ }^{23}$

En este contexto, la teoría crítica proveniente de la Escuela de Frankfurt es afirmada como instrumento de emancipación que evidencia las relaciones "entre los ámbitos económico, político, social, cultural y psíquico" ${ }^{24}$. No obstante, su apropiación en el campo del trabajo social ha sido menor (ubicándose aquí lo planteado por Matus) si se considera que sus repertorios de investigación e intervención crítica se han afianzado al cobijo del marxismo, tanto en clave althusseriana (para buena parte del movimiento de reconceptualización) o luckasiana, en el caso del trabajo social crítico. Más allá de sus profundas diferencias en cuanto a los ejes de análisis (en el campo filosófico epistemológico para Althusser, en la ontología materialista para Luckacs), podemos destacar que el sujeto no solo está determinado por su condición sociohistórica de clase, sino que además dispone de la posibilidad de participar en la activación-intensificación de procesos históricos de lucha social, plegándose a un proyecto ético político. Para el caso del trabajo social en clave histórico-crítica, esto se patenta en la invitación a consolidar la democracia y la ciudadanía por vía de "la ampliación progresiva de la esfera pública" en una defensa "intransigente de los derechos humanos" contra las múltiples manifestaciones de la cuestión social ${ }^{25}$.

Desde este ángulo, que en nombre de la objetividad rechaza el positivismo y el subjetivismo, el sujeto de la intervención es construido como ser social a través

\footnotetext{
23 Guido Galafassi, "La teoría crítica de la Escuela de Frankfurt y la crisis de la idea de razón en la modernidad", Contribuciones desde Coatepec n. ${ }^{\circ} 2$ (2002): 9.

24 Karen Healy, Trabajo social: Perspectivas contemporáneas (Madrid: Ediciones Morata, 2001), 30.

25 Marilda Iamamoto, El servicio social en la contemporaneidad. Trabajo y formación profesional (São Paulo: Cortez Editora, 2003$), 170$.
} 
de elementos estructurales, coyunturales y teóricos que rastrean su emergencia concreta a partir de la materialidad del trabajo como praxis histórica inmersa en las contradicciones del capitalismo, por lo cual:

[...] entender la complejidad del ser social en la sociedad capitalista implica reconocer la "cuestión social" a partir de la contradicción capital-trabajo y explicitar sus manifestaciones en la cotidianidad de la vida social. Implica también movilizar conocimientos teóricos para comprender que el sujeto de intervención, en tanto objeto, está determinado por la realidad concreta y tiene existencia objetiva independientemente de la consciencia. ${ }^{26}$

Al margen de otras posibilidades epistémico-teóricas de constitución del sujeto (de intervención-investigación) del trabajo social, cercanas a comprensiones socio-constructivistas, del interaccionismo simbólico o posestructura$\operatorname{listas}^{27}$ que no analizamos aquí por razones de brevedad, podemos señalar que, al retomar y participar activamente en la producción y uso profesional-disciplinar de estas comprensiones teórico-conceptuales de las ciencias sociales, no se ha interrogado de manera sostenida sobre su incidencia en la dimensión política de los procesos de subjetivación, esto es, en relación con el lugar de los sujetos (sus posiciones y posicionamientos) y las estructuraciones sociales en la producción, reproducción o cambio social. De este modo, procurando la superación del sufrimiento humano, se han buscado posibilidades prácticas de cambio que ponen el énfasis en la individualidad o la transformación de aspectos estructurales: la cultura, la economía, la participación política. Con esto se ha abstraído uno de los debates modernos del que estas teorías hacen parte: sobre lo humano como producto de determinaciones (biológicas, históricas, sociales) externas o el resultante del ejercicio de la voluntad.

Así mismo, se encuentra que hay un efecto de naturalización del proceso de construcción social del sujeto de intervención y de los modelos de intervención social, de modo que en la mediación simbólica podemos encontrar trazas éticas y referencias de sentido que, desde el nivel intersubjetivo y subjetivo, condicionan procesos de subjetivación no interrogados, dando lugar a un proceso de invención de un sujeto deficitario que encubre la alteridad en su potencia política y justifica la emergencia de un sujeto experto con capacidad profesional de ayuda, donde la intervención es naturalizada como acción técnica, sin considerar su estructuración como constructo sociocultural moderno. En relación con el primero de estos sujetos, se acude a conceptos hegemonizados de sociedad y de sujeto que operan como ideales normativos bajo ideales de progreso-desarrollo. Consecuentemente, la intervención se teje como dispositivo de manipulación colonial sobre la base del binomio jerarquizado: protección-control. Este acontece con recurso a estándares predefinidos para inducir cambios cualitativos

26 Sandra Elizabet Mancinas Espinoza, “La construcción’ del sujeto de intervención en trabajo social. Un análisis histórico crítico", Praia Vermelha, vol. 2, n. ${ }^{\circ} 24$ (2014): 384.

27 Ibíd. 
significados como beneficios (hacia individuos, grupos y comunidades cosificadas) desde visiones externalistas y modernizantes ${ }^{28}$.

A decir de Zúñiga ${ }^{29}$, se fija así la mirada hacia el otro desde fuera. Una mirada recubierta de pretensiones de empatía, solidaridad, implicación militante, que otorgan al otro los atributos de un objeto receptor de la acción (paciente, cliente, beneficiario o educando) en términos de altruismo, servicio, objetividad científica, con lo que se inauguran dos aspectos éticamente problemáticos: la irreflexividad sobre la formación y el papel del profesional en la configuración de una relación eficaz y la indiferenciación / obviamiento de actor (trabajo social) y sujeto (trabajador social), no mirando su actuar y su acción efectiva y reduciendo el sujeto a su subjetividad, de modo que arriba a la irresponsabilidad por cuanto ideologiza la teoría de la acción y produce una distorsión epistemológica, en la que la generosidad pasa a ser ausencia de reflexión concreta sobre el impacto de la labor profesional del trabajador social.

En suma, estas visiones se aproximan en buena medida a los supuestos del interculturalismo funcional, esto es, el reconocimiento exotizante de las diferencias en contextos naturalizados por efecto de una ausencia de problematización de las relaciones asimétricas de poder que las atraviesan. Con esto no se cuestionan los sistemas de opresión y se propicia su reproducción por vía de la acción profesional. En dirección contraria, estimamos preciso asumir la racionalidad crítica y situada para atender la invitación de Mellizo, Vélez y Jiménez ${ }^{30}$ en torno a propiciar una producción teórica orientada a la renovación del acervo profesional crítico y comprometido con la transformación social, para lo cual es útil la interculturalidad crítica.

\section{Interculturalidad crítica: propuesta para la reconfiguración del otro en la intervención del trabajo social}

Tales resignificaciones de la investigación promueven problematizaciones contextualizadas en el marco de lo social, posibilitando para el trabajo social interlocutar y co-construir con otras disciplinas alternativas sociales cimentadas en el posicionamiento y reflexión en torno a la relación que nosotros planteamos con la realidad, los objetos de intervención, las metodologías, los cuerpos teóricos y las subjetividades, reconociendo que tal relación nos involucra, nos mueve en la búsqueda de la interculturalidad crítica, debe ser nuestro compromiso apropiar, formar y generar discusiones críticas ante nociones y comprensiones del mundo generadas en otro lugar alterno al "científico-intelectual" tradicional, las cuales promueven que "la ciencia y el conocimiento no son singulares y únicos,

28 Juan Blanco López, "La construcción social del sujeto de intervención. Los modelos implícitos en los procesos de intervención social", Acciones e investigaciones sociales $n .^{\circ}$ extra 1 (2006): 443.

29 Ricardo Zúñiga, "Haciendo emerger actores y sujetos: el trabajador social como actor y sujeto", Revista de Trabajo Social 2 , n. ${ }^{\circ} 4$ (1996).

30 Wilson Mellizo, Gerardo Vélez y David Jiménez, "Importar, transformar y construir: Diálogos entre Trabajo Social y Ciencias Sociales en nuestra América", en Trabajo social: ensayos sobre tendencias y retos en Colombia, eds. Carolina Bautista y Wilson Mellizo (Bogotá: Ediciones Unisalle, 2017), 53-137. 
e identificar los conocimientos ancestrales como conocimientos científicos y tecnológicos, relevantes y necesarios para todos [...] extiende la interculturalidad al campo epistémico"31.

Ante ello surge la interculturalidad crítica que advierte sobre el posicionamiento de los diferentes saberes y concepciones otros, ante el universalismo del conocimiento único que se encuentra, como lo menciona por Alejandro Álvarez ${ }^{32}$, en crisis como discurso intelectual. Dicha perspectiva reconoce el significado político de otras voces que cuestionan el modelo hegemonizado de dominación, atribuyendo a la cultura y al lenguaje un papel fundamental como escenario de resistencia a las formas de dominación de poder que expresa la subjetivación, posibilitando desde allí un tránsito hacia la reivindicación del tradicional sujeto-otro. Tal abordaje debe orientarse a posicionar la interculturalidad crítica, visibilizando los lugares de opresión y exclusión, desde los cuales se ha constituido, según Walsh: "[...] la exclusión, negación y subalternización ontológica y epistémico-cognitiva de los grupos y sujetos racializados por las prácticas - de deshumanización y subordinación de conocimientos - que privilegian a unos sobre otros" ${ }^{\prime 3}$.

La interculturalidad crítica devela, en el escenario formativo y profesional, fisuras en el reconocimiento de la diversidad, por ejemplo en nuestro país caracterizado por la riqueza en su diversidad pero también con graves vulneraciones a los derechos humanos consagrados en una Constitución que reconoce la pluriculturalidad -, es clave poner en escena el concepto de diversidad con el fin de trascender los desarrollos tradicionales que ubican la interculturalidad exclusivamente desde el plano étnico, puesto que reconocer las diferencias sociales, culturales, étnicas, territoriales, generacionales, de género, de realidades, condiciones, situaciones y experiencias que rodean nuestra cotidianidad, contribuye a generar diálogos interculturales ${ }^{34}$ que afecten la segregación, discriminación y exclusión, contemplando la diversidad, según Sánchez como: "[...] el reconocimiento de la otra persona, de su individualidad, originalidad e irrepetibilidad, y supone promover el respeto a esa individualidad y la atención y adecuación a los ritmos personales" 35 .

En torno a la interculturalidad, Nubia Agudelo y Norman Estupiñán reconocen esta perspectiva como un diálogo en condiciones de horizontalidad mediado por la cultura, lo cual posibilita el crecimiento en las comprensiones, emociones y relaciones entre sujetos que históricamente han padecido la segregación y exclusión, producto del modelo de dominación imperante que inva-

31 Catherine Walsh, "Interculturalidad crítica y educación intercultural" (ponencia, Seminario "Interculturalidad y Educación Intercultural”, La Paz, Instituto Internacional de Integración del Convenio Andrés Bello, 9-11 de marzo de 2009).

32 Alejandro Álvarez, Los discursos otros. Críticas al universalismo occidental (Bogotá: Desde abajo, 2014).

33 Walsh, "Interculturalidad crítica".

34 Fernanda Torres, "Educación para la paz y formación profesional: aproximación desde la investigación documental", Praxis \& Saber vol. 10, n. ${ }^{\circ} 22$ (2019): 161.

35 Iván Sánchez, La interculturalidad desde la perspectiva de la inclusión socioeducativa (Santa Marta: Editorial Unimagdalena, 2013), 14. 
lida la diversidad, puesto que la interculturalidad implica la emancipación y la reivindicación frente a las expresiones hegemónicas de desigualdad ${ }^{36}$.

Explorar el concepto de la diversidad, la inclusión y la interculturalidad convoca a resignificar la lectura tradicional planteada desde el marco socio jurídico y paradigmas funcionales sobre los derechos humanos, puesto que la discusión por la diversidad, propuesta por Iván Sánchez ${ }^{37}$, se promueve una relación asertiva y autónoma con el Estado, que posibilite el reconocimiento de los diferentes grupos sociales, étnicos y culturales, con capacidad para la participación y la acción política.

Para alcanzar la visión de la interculturalidad crítica en la formación e intervención del trabajo social, se pretende contemplar la alteridad como eje transversal, toda vez que esta permite transitar desde las prácticas de tolerancia que no promueven el reconocimiento y el diálogo, hacia la apuesta por el diálogo intercultural desde la generación de vínculos y puentes de validación y posicionamiento del otro en su diversidad, por lo cual la noción de alteridad, según Cabaluz propone:

[...] una visión crítica, novedosa y contra-hegemónica, por lo mismo, podemos afirmar que gran parte de la criticidad de la Filosofía de la Liberación dusseliana proviene de su opción por la Alteridad, por el/la Otro/a excluidola, marginado/a, periférico/a y dominado/a. Rechazar la filosofía que emerge desde el ego cartesiano, el yo conquisto hispánico o el yo voluntad de poder, permite la irrupción en el campo filosófico de los sujetos oprimidos y su materialidad: su rostro, su voz, su pobreza, su grito. ${ }^{38}$

Este autor reconoce como esos "otros/as" excluidos las víctimas de la dominación por raza, clase, etnia, posición económica y política, entre otras distinciones, ejemplificadas en mujeres, niños y niñas, campesinos, colectivos y movimientos sociales, pobres, trabajadores, habitantes de calle, indígenas, entre otros.

Ante ello emergen formas "otras" de formación e intervención que reconocen pedagogías alternativas que contribuyen al empoderamiento de los profesionales y los sujetos ${ }^{39}$, como lo es la pedagogía de la alteridad, enunciado por Enrique Dussel, quien plantea transitar del concepto de tolerancia al concepto de solidaridad como expresión de la alteridad, toda vez que la primera noción acude a una perspectiva segregadora y excluyente en torno al lugar de la ciudadanía occidental y la fraternidad, por lo que propone acudir al concepto de solidaridad entendido como:

36 Nubia Agudelo y Norman Estupiñán, “Formar sujetos sociales para una ciudadanía intercultural”, en América Latina y el Mediterráneo: ideas en contacto. Actas del XIV Congreso de la FIEALC, ed. Efthimía Pandís (Madrid: Ediciones del Orto, 2010).

37 Sánchez, La interculturalidad.

38 Fabián Cabaluz, Entramando Pedagogías Críticas Latinoamericanas. Notas teóricas para potenciar el trabajo político-pedagógico comunitario (Santiago de Chile: Editorial Quimantú, 2015), 72.

39 Celina Trimiño Velásquez y Luisa Amézquita, "Reflexiones desde la universidad sobre educación en derechos humanos y para la paz", Revista Historia de la Educación Latinoamericana 20, n. 31 (2018): 103. 
[...] una pulsión de alteridad, un deseo metafísico (E. Levinas) por el otro que se encuentra en la exterioridad del sistema donde reina la tolerancia y la intolerancia. Es un hacerse-cargo (eso significa re-spondere: tomar a cargo (spondere) del otro, reflexivamente (re-)) ante el tribunal del sistema que acusa porque se asume a la víctima de la injusticia y, por ello, aparece como el señalado, como el injusto, culpable, reo, como el rehén en el sistema en nombre del otro. ${ }^{40}$

Esta apuesta epistémica se fundamenta en el concepto de trasmodernidad, como crítica al modelo hegemónico, antropocéntrico occidental, que promueve procesos de dominación y colonialidad eurocéntrica. Tal concepto posibilita reconocer la dependencia y exclusión desde el modelo sistema-mundo, que invisibiliza y niega la diversidad y la multiculturalidad, que trasciende la idea de modernidad impuesta por el modelo capitalista.

La alteridad y su pedagogía, moviliza para la formación una apertura en la comprensión y relación con el/la otro/a, desde el diálogo con diferentes y diversas epistemologías que movilizan transformaciones y transiciones en sí mismo; por ello, generar tal apertura epistémica que sensibilice las emociones y la cognición a través de la denominada ética de la alteridad, fundada bajo los principios enunciados por María Córdoba y Claudia Vélez: La necesidad de colaboración y relación de los seres humanos, el compromiso de reconocer al otro desde su dignidad y condición diferencial, la pertinencia del cuidado de sí y del otro, la proyección del ser, la naturaleza constructiva de lo social, y la importancia de la relación y la responsabilidad con la existencia del otro ${ }^{41}$.

La apuesta por la perspectiva intercultural crítica debe incluir propuestas de formación profesional bajo corrientes críticas que cuestionan la ciudadanía desde la perspectiva de formación integral hegemónica, desafiando en lo macro social las relaciones de poder inmersas en escenarios con políticas públicas educativas que no articulan diferentes ámbitos de la educación con la sociedad, por primar respuestas a condiciones funcionales al modelo económico de mercado y el colonialismo, y en lo micro social, en el interior de los centros educativos y su dinamismo práctico en la sociedad.

\section{CONCLUSIÓN}

El hilo que va de la preocupación ética a la acción profesional pasa por un proceso de doble subjetivación, sostenido por diferentes articulaciones discursivas que le confieren sentidos específicos en un contexto histórico, social, económico, político y cultural. En este escenario es pertinente indicar que, en el trabajo social, se han asumido denominaciones conceptuales que prefiguran una imagen del otro, del sí mismo del-a profesional y de las relaciones formativas y

40 Enrique Dussel, Deconstrucción del concepto de "tolerancia" (De la intolerancia a la solidaridad) (México: UAM-Iz, 1998) http://red. pucp.edu.pe/wp-content/ uploads/biblioteca/090508.pdf (septiembre de 2019).

41 María Córdoba y Claudia Vélez, "La alteridad desde la perspectiva de la transmodernidad de Enrique Dussel”, Revista Latinoamericana de Ciencias Sociales, Niñez y Juventud 14, n. ${ }^{\circ} 2$ (2016): 1008. 
profesionales, de modo que las tramas discursivas hacen parte de los recursos de invención del otro, en las que se incorporan comprensiones antropológicas ligadas a los estatutos político-culturales de occidente.

Se identifica así que, para el periodo estudiado, en el campo del trabajo social hay dos miradas. Por una parte, una mirada consolidada que alude al continuum de la explicación estructuralista de lo social, situada eurocéntricamente en la episteme de la primera y la segunda modernidad, donde el otro es producido-condicionado por estructuras (y relaciones) objetivas, frente a las cuales deviene en sujeto (objetivado) de la intervención profesional, bien para ajustarse de manera individualizada a los imperativos modernos de normalización (bajo diversas agendas de intervención filiadas al mercado o al ámbito de las políticas públicas), o bien para confrontar colectivamente y desde abajo las estructuras socioeconómicas de dominación de clase. Así, con recurso a la mirada estructuralista, el otro se afirma como una invención referida, en términos generales, a una alteridad deficiente, en función de la cual se legitima socialmente la configuración de un campo de profesionalización salvífico, cuya identidad es aún imprecisa y susceptible de activarse en provecho de diversos proyectos ético-políticos.

Por otra parte, sin pretender desconocer comprensiones microsociales (subjetivistas, socio-constructivistas, interaccionismo simbólico) o posestructuralistas en el campo del trabajo social, se aboga aquí por una segunda mirada en la que la alteridad se torna en piedra angular para la activación de procesos de formación, investigación e intervención, proyectados ético-políticamente hacia la emancipación social dignificante, la ampliación de los sentidos de la democracia en perspectiva crítica, la construcción de justicia social, la vigencia material de derechos en contra de las lógicas de opresión, discriminación, expoliación, negadoras de la diferencia. Desde esta mirada se comprende que el continuum estructuralista aporta importantes elementos para la problematización crítica de la realidad social, pero no necesariamente ha de prescribir los modos de subjetividad para ordenar las relaciones sociotécnoprofesionales, sino que la alteridad ha de emerger con su potencia política en el tejido particular de una relación profesional críticamente situada y soportada desde la demodiversidad como sustrato de la multiplicidad de las ciudadanías y de la diversidad de espacialidades y tópicos de conflicto social.

Esta segunda mirada, alineada con la interculturalidad crítica, apuesta por el reconocer y potenciar al sujeto político y la subjetividad política como instancias plurales que confieren dinamismo social a la historia, ángulo desde el cual se reconoce al trabajador y la trabajadora social y los grupos poblacionales con los que desarrolla su labor de intervención e investigación como alteridades en devenir que coparticipan (racional y sensiblemente) en procesos de producción de acontecimientos de transformación de diferentes escalas de la realidad social. Esto reclama una forma de comprender y comprenderse, problematizar y problematizarse éticamente como sujeto autónomo-heterónomo inscrito en la 
trama cotidiana de la vida, en sus anudamientos históricos, en las codificaciones sociales de clase, género, filiación étnica, política, ideológica y cultural.

Desde esta mirada, el trabajo social se configura como profesión y disciplina a la luz de procesos de formación, investigación e intervención éticamente comprometidos con el acogimiento de la alteridad en el nivel relacional (intersubjetivo e histórico), en el que la vida humana se teje y desenvuelve cotidianamente, heredando y asumiendo como objetos de su reproducción y transformación sentidos y prácticas concretas en torno a lo distintivamente humano en sus expresiones individuales y colectivas, entre el espacio de experiencia y el horizonte de espera activados en la temporalidad viva del presente potencial (Zemelman). Más específicamente, a la luz de la preocupación ética vitalista y del compromiso político con la dignificación social, jurídica y política de lo humano, se asume aquí que los procesos de investigación y de intervención desde el trabajo social derivan sus condiciones de legibilidad y de legitimidad social y académica del responder críticamente a las necesidades contextuales y existenciales de reconocimiento para nutrir posibilidades de acción (molares-colectivas) transformadoras del sufrimiento humano por vías del diálogo entre y con diversos actores y saberes sociales.

Si bien estas comprensiones, en tanto que filiadas al pensamiento crítico, dialogan con la tradición del pensamiento crítico correspondiente a la segunda modernidad y con la sistemática problematización en el ámbito postestructuralista (especialmente en torno a su carácter universalista fundado en una visión trascendental del sujeto como centro de la razón, la moral y el lenguaje), no se ubican en el mismo campo ontológico-epistémico, ni comportan una misma vocación ético-política en consideración de su locus histórico de producción. La teoría crítica en general, así como las problematizaciones postestructuralistas, surgen como una crítica interna (desde la totalidad ontológica occidental) al proyecto de modernidad en dirección de alcanzar su mayor potencial emancipatorio o de eliminarlo, en tanto que la perspectiva de interculturalidad crítica es planteada desde el afuera de la modernidad (como ontología europea imperial), esto es, desde la colonialidad (la exterioridad como negatividad ontológica) en dirección de la liberación-descolonización ${ }^{42}$.

La otra cara de la modernidad como discurso situado en la experiencia concreta del ser Otro en condición de dominación colonial, nos permite identificar en la historia la dimensión geopolítica del saber y su expansión epistemicida ${ }^{43}$, cuyos legados se extienden al presente de globalización neoliberal, legitimando la primacía total del mercado a través de concepciones propias del pensamiento único y su reproducción de epistemes de la invisibilidad y de ignorancia, frente a las cuales es preciso avanzar en dirección de destotalizar el discurso sobre el Otro para propiciar dinámicas de reconocimiento efectivo.

42 Enrique Dussel, Debate en torno a la ética del discurso de Apel (México: Siglo XXI, 1994).

43 Boaventura de Sousa Santos, Una epistemología del Sur. La reinvención del conocimiento y la emancipación social (México: CLACSO, Siglo XXI editores, 2009). 
En tal sentido, la interculturalidad emerge como categoría fundante para el trabajo social, posicionada desde los discursos de derechos de tercera generación, cooperativos o de los pueblos, que promulga una construcción social que trasciende la gestación de intercambios desiguales, en los que prima una cultura sobre otra, advirtiendo cómo la intervención profesional requiere el posicionamiento de los diferentes saberes y concepciones otros, ante el universalismo del conocimiento único, desde el cuestionamiento a las epistemologías dominantes que generan exclusión, odio, desigualdad y terror para el ejercicio de la subjetividad, producto de la diferencia y la diversidad que hace parte de nuestra condición humana. Este complejo escenario requiere de transformaciones culturales que deben atravesar las creencias, conceptos, práctica e imaginarios de cada uno de los integrantes de nuestra sociedad y de la profesión, para afianzar un nuevo ethos desde la promoción de la alteridad y el goce del buen vivir para todas y todos.

La resignificación del otro desde la alteridad propone, como desafío a la formación profesional de trabajadores sociales, la humanización de la universidad, dotando de afectividad y emocionalidad este proceso ${ }^{44}$, en sintonía con los saberes múltiples y la diversidad, lo cual implica intencionar abordajes pedagógicos que se reconozcan desde la decolonialidad: contextos de heterogeneidad histórica, contenidos contextualizados y situados, relaciones diversas entre las subjetividades de los actores propios de esta interacción, pedagogías liberadoras y procesos de humanización crítica intercultural ${ }^{45}$.

Por ello, en los procesos educativos y sociales es clave cuestionar la formación para la generación de profesionales críticos, propositivos y autónomos, que sean capaces de hacer discusiones y reflexiones críticas ante imposiciones heterónomas frente a las estructuras sociales que mantienen el statu quo, impulsando intercambios de pensamientos a la cooperación y a solidaridad. Por ende, es necesario promover la autonomía y la alteridad, como aportes a la no exclusión ni discriminación (étnica, ideológica, orientación e identidad sexual, etc.), para configurar sujetos capaces de transformar la realidad de su entorno desde una intervención intercultural, para brindar una mirada contextual en la toma de posición y movilización social, para la comprensión de los distintitos lugares de enunciación y discursos que se construyen en la academia y en las comunidades.

\section{REFERENCIAS}

Álvarez, Alejandro. Los discursos otros. Críticas al universalismo occidental. Bogotá: Desde abajo, 2014. Alvear, Rafael. "La sociología clásica y el destierro del ser humano". Cinta de Moebio. Revista de Epistemo-

44 María Aristizábal Salazar y Arlex Castaño Galeano, “Asemillar. Reflexiones pedagógicas para la formación desde la perspectiva crítica del Trabajo Social Intercultural y Decolonial”, en Experiencias con diversidades sociales. Desde Trabajo Social Intercultural y Decolonial (Medellín: Universidad de Antioquia / Pulso \& Letra Editores, 2018), 32. 


\section{en la formación e intervención del trabajo social}

logía de las Ciencias Sociales n. 59 (2017).

Agudelo, Nubia y Norman Estupiñán. "Formar sujetos sociales para una ciudadanía intercultural". En América Latina y el Mediterráneo: ideas en contacto. Actas del XIV Congreso de la FIEALC, editado por Efthimía Pandís. Madrid: Ediciones del Orto, 2010.

Aristizábal Salazar, María y Arlex Castaño Galeano. “Asemillar. Reflexiones pedagógicas para la formación desde la perspectiva crítica del Trabajo Social Intercultural y Decolonial”. En Experiencias con diversidades sociales. Desde Trabajo Social Intercultural y Decolonial. Medellín: Universidad de Antioquia / Pulso \& Letra Editores (2018).

Blanco López, Juan. "La construcción social del sujeto de intervención. Los modelos implícitos en los procesos de intervención social". Acciones e investigaciones sociales n.․ extra 1 (2006).

Cabaluz, Fabián. Entramando Pedagogías Críticas Latinoamericanas. Notas teóricas para potenciar el trabajo político-pedagógico comunitario. Santiago de Chile: Editorial Quimantú, 2015.

Carballeda, Alfredo. La intervención en lo social. Exclusión e integración en los nuevos escenarios sociales. Buenos Aires: Paidós, 2002.

Córdoba, María y Claudia Vélez. “La alteridad desde la perspectiva de la transmodernidad de Enrique Dussel". Revista Latinoamericana de Ciencias Sociales, Niñez y Juventud 14, n. ${ }^{\circ}$ (2016): 1001-1015.

De Sousa Santos, Boaventura. Una epistemología del Sur. La reinvención del conocimiento y la emancipación social. México: CLACSO, Siglo XXI editores, 2009.

Dussel, Enrique. Deconstrucción del concepto de "tolerancia" (De la intolerancia a la solidaridad). México: UAM-Iz, 1998. http://red.pucp.edu.pe/wp-content/ uploads/biblioteca/090508.pdf. (septiembre de 2019).

Dussel, Enrique. Debate en torno a la ética del discurso de Apel. México: Siglo XXI, 1994.

Florián B., Maribel. “¿Es la ciencia heteronormativa? Reflexiones en torno a cómo la teoría social contemporánea ha abordado el tema de las relaciones amorosas". En Pensar las Ciencias Humanas y Sociales. Debates Interdisciplinarios. Editado por Jenny Alexandra Jiménez. Bogotá: Fundación Universitaria Los Libertadores, 2015.

Galafassi, Guido P. "La teoría crítica de la Escuela de Frankfurt y la crisis de la idea de razón en la modernidad". Contribuciones desde Coatepec n. 2 (2002): 4-21.

Healy, Karen. Trabajo social: Perspectivas contemporáneas. Madrid: Ediciones Morata, 2001.

Iamamoto, Marilda. El servicio social en la contemporaneidad. Trabajo y formación profesional. São Paulo: Cortez Editora, 2003.

Iamamoto, Marilda. Servicio social y división del trabajo. Un análisis crítico de sus fundamentos. São Paulo: Cortez Editora, 1997.

IFSW-IASSW. “Definición global del trabajo social. Melbourne: IFSW- IASSW, 2014. https://www.ifsw. org/what-is-social-work/global-definition-of-social-work/definicion-global-del-trabajo-social/

Lutz, Bruno. "Estructura y Sujeto: Perspectivas teóricas desde las Ciencias Sociales". Cinta de Moebio. Revista de Epistemología de Ciencias Sociales n. ${ }^{\circ} 29$ (2007): 155-166.

Malagón Bello, Edgar. Fundamentos de trabajo social. Bogotá: Universidad Nacional de Colombia, 2012.

Mancinas Espinoza, Sandra Elizabet. “'La construcción' del sujeto de intervención en trabajo social. Un análisis histórico-crítico". Praia Vermelha 24, n. ${ }^{\circ} 2$ (2014).

Martín R., Luisa. "El análisis crítico del discurso. Fronteras y exclusión social en los discursos racistas". En Análisis del discurso. Manual para las Ciencias Sociales, editado por Lupicinio Íñiguez. Barcelona: Editorial UOC, 2006.

Matus, Teresa. Propuestas contemporáneas en trabajo social: hacia una intervención polifónica. Buenos Aires: Espacio Editorial, 1999.

Mellizo, Wilson, Gerardo Vélez y David Jiménez. “Importar, transformar y construir: Diálogos entre Trabajo Social y Ciencias Sociales en nuestra América". En Trabajo social: ensayos sobre tendencias y retos en Colombia, editado por Carolina Bautista y Wilson Mellizo. Bogotá: Ediciones Unisalle, 2017.

Montaño, Carlos y Elisabete Borginai. El debate metodológico de los 80/90. El enfoque ontológico versus el abordaje epistemológico. Metodología y servicio social hoy en debate. São Paulo: Cortez Editora, 2000.

Morales Mosquera, María y Nora Muñoz Franco. "Desafíos para la formación desde el Trabajo Social en contextos diversos". En Experiencias con diversidades sociales. Desde Trabajo Social Intercultural y Decolonial. Medellín: Universidad de Antioquia / Pulso \& Letra Editores, (2018). 
Sánchez, Iván. La interculturalidad desde la perspectiva de la inclusión socioeducativa. Santa Marta: Editorial Unimagdalena, 2013.

Torres Gómez, Fernanda. "Educación para la paz y formación profesional: aproximación desde la investigación documental". Praxis $\mathcal{E}$ Saber 10, n. ${ }^{\circ} 22$ (2019): 143-167.

Torres Gómez, Fernanda. "Reflexividad en trabajo social: horizontes desde la formación integral para la investigación y la intervención". En Reflexiones sobre la comprensión de la investigación y la intervención social en formación en Trabajo Social, editado por Maribel Florián B. Bogotá: Ediciones Unisalle, 2018.

Travi, Bibiana. La dimensión técnico-instrumental en Trabajo Social. Reflexiones y propuestas acerca de la entrevista, la observación, el registro y el informe social. Buenos Aires: Espacio Editorial, 2006.

Trimiño Velásquez, Celina y Luisa Amézquita. "Reflexiones desde la universidad sobre educación en derechos humanos y para la paz". Revista Historia de la Educación Latinoamericana 20, n. 31 (2018): 101-124.

Tubino, Fidel. "La interculturalidad crítica como proyecto ético-político". Lima: Encuentro continental de educadores agustinos, 24-28 de enero de 2005. http://oala.villanova.edu/congresos/educación/lima-ponen-02.html

Van Dijk, Teun. "El análisis crítico del discurso". En Estudios sobre el discurso. Una introducción interdisciplinaria, compilación y prólogo de T. van Dijk. Barcelona: Gedisa, 2000.

Walsh, Catherine. "Interculturalidad crítica y educación intercultural". Ponencia presentada en el Seminario "Interculturalidad y Educación Intercultural", La Paz, Instituto Internacional de Integración del Convenio Andrés Bello, 9-11 de marzo de 2009.

Yáñez Pereira, Víctor. “Visibilidad/ invisibilidad en la intervención del trabajo social: pistas para la revisitación de las pautas transaccionales de la disciplina con el mundo de lo social". En Naturaleza, desafios y perspectivas contemporáneas de la intervención en trabajo social. Memorias I. Seminario internacional. Buenos Aires: Editorial Lumen-Humanitas, 2011.

Zúñiga, Ricardo. "Haciendo emerger actores y sujetos: el trabajador social como actor y sujeto". Revista de Trabajo social 2, n. ${ }^{\circ} 4$ (1996): 7-21.

Cómo citar:

Torres Gómez, Fernanda; Velez Villafañe, Gerardo. “Resignificar al otro: Configuraciones de la interculturalidad en la formación e intervención del trabajo social" Revista Historia de la Educación

Latinoamericana. vol. 22 No. 34 (2020): 161-180

DOI: https://doi.org/10.19053/01227238.10901

(c) $\mathbb{( 1 ) \Theta 9}$ Esta obra está bajo una licencia Creative Commons.

Reconocimiento-No Comercial-Sin Obra Derivada 2.5 Colombia. 